\title{
Bioprosthesis versus Mechanical Valve Heart Prosthesis: Assessment of Quality of Life
} José Carlos Molero Junior, ${ }^{\circledR}$ Rodrigo Daminello Raimundo, ${ }^{\circledR}$ Joice Anaize Tonon do Amaral, ${ }^{2}{ }^{\circledR}$ Luiz Carlos de Abreu, $^{1 \odot}$ João Roberto Breda' ${ }^{1 \odot}$

Centro Universitário Saúde ABC,' Santo André, SP - Brazil

Faculdade de Medicina da Universidade de São Paulo (FMUSP), ${ }^{2}$ São Paulo, SP-Brazil

\section{Abstract}

Background: The aim of this study was to evaluate the QoL of patients undergoing heart valve replacement using the SF-36 questionnaire, compare it between patients with mechanical prosthesis and patients with bioprosthesis, and correlate the results with sociodemographic variables.

Objective: To assess the QoL of patients undergoing heart valve replacement and compare it between patients with bioprosthetic valves and patients with mechanical prosthetic valves.

Methods: We included 36 consecutive patients ( 16 men) with a mean age of 51 years and six months, who underwent mitral or aortic valve replacement from September 2007 to December 2011. The study was conducted between March and May 2012 and involved the application of the SF-36 survey and a sociodemographic questionnaire. Statistical tests were performed, and data are expressed as absolute frequency and percentile, and median and interquartile range (P25 and P75) (Mann-Whitney test), considering a significance of 95\%.

Results: The average time of surgery was 32.5 months (8-61 months). Participants were asked about the practice of physical activity, and $41.7 \%$ were physically active. For the SF-36 domains, the highest scores were observed for the social domain whereas the lowest scores were found for mental health, with a mean of 89.25 and 54.44, respectively. In the statistical analysis, we found statistically higher values in emotional functional for patients with mechanical valve prosthesis $(\mathrm{p}=0.0084)$.

Conclusion: The QoL of the patients undergoing heart valve replacement improves considerably after the surgery, except for the mental health domain, probably due to the low practice of physical activity. The type of prosthesis seems not to influence the QoL or the patients in the late postoperative period. (Int J Cardiovasc Sci. 2020;33(1):36-42)

Keywords: Quality of Life; Sickness Impact Profile; Stress, Psychological; Heart Valve Prosthesis; Mitral Valve; Aortic Valve.

\section{Introduction}

Heart valve diseases cause substantial impairment in daily life due to symptoms like angina, dyspnea, and tiredness during normal activities. It is considered a disabling condition as it is one of the main causes of heart failure, with a negative impact on quality of life (QoL). ${ }^{1}$ The treatment of heart valve disease is surgical repair or replacement of the affected valve, which can significantly increase survival and control and reduce the symptoms of the disease. ${ }^{1,2}$

Despite advances in the development of valvular prothesis over the years, current devices have some drawbacks, including the need of anticoagulation in patients with mechanical prostheses. ${ }^{3}$ According to a review conducted in 2011, the choice of the prosthesis should be made with caution, based on the best alternatives for each patient. There is currently no

Mailing Address: Rodrigo Daminello Raimundo

Centro Universitário Saúde ABC - Avenida Príncipe de Gales, 667. Postal Code: 09060-590, Bairro Príncipe de Gales - Santo André, SP - Brazil.

E-mail: rodrigo.raimundo@fmabc.br 
valvular prosthesis available with all the characteristics of an ideal prosthesis. ${ }^{4}$

Most complications of valvular prosthesis implantation are probably related to the patient rather than the prosthesis per se. ${ }^{5}$ In recent years, studies on QoL have been one the main objects of health studies, and has been the focus of discussion forums, lay press, and marketing of products and services. ${ }^{6,7}$

One of the methods for assessing QoL is the Medical Outcomes Study (MOS) 36-Item Short Form Health Survey (SF-36), which was validated in Portuguese by Ciconelli et al., ${ }^{8}$ This is a generic tool for assessing QoL, easy to apply and understand and relatively short when compared to others. The instrument can be used in individuals older than 12 years and administered either individually or in groups and evaluate physical and mental health in clinical practice. For each question of the SF-36, a score from 0 to 100 is assigned, where a low score indicates poor health perception, loss of function and pain, and a high score indicates good health perception, preserved function and absence of pain. ${ }^{9-11}$

The main of this study was to assess the QoL of patients undergoing heart valve replacement and compare it between patients with bioprosthetic valves and patients with mechanical prosthetic valves.

\section{Methods}

The study was approved by the Ethics Committee of the ABC Medical School (approval number 043/2011). Between September 2007 and December 2011, 36 patients underwent mitral and/or aortic valve replacement and were invited to participate in a descriptive study about QoL, using the SF-36 health survey and a sociodemographic questionnaire.

The convenience sample was composed of 16 men and 20 women, consecutively included in the study. All participants signed the informed consent form.

\section{SF-36 health survey}

The SF-36 survey is a generic questionnaire that assesses multiple dimensions of health-related QoL, which is widely used due to its high applicability and practicality. It is composed of 36 items grouped in eight scales or domains: functional capacity, physical functioning, pain, vitality, social functioning, emotional role and mental health. Among the 36 items, one item specifically compares current with previous (one year or more) perception of health status. ${ }^{8}$

Responders are asked to assign a rate from 0 to 100 , where 0 denotes the worst health status and 100 denotes the best health status. ${ }^{8}$

\section{Sociodemographic questionnaire}

This questionnaire was used to evaluate personal data (age, sex, height, weight, marital status), diagnosis (type of valve replacement), educational background, occupation, risk factors (including chronic obstructive pulmonary disease, COPD, systemic arterial hypertension, smoking and diabetes mellitus) and income of the patients.

All interviews were conducted by the main researcher. The interviews were scheduled individually, by telephone, and lasted approximately 30 minutes.

\section{Statistical analysis}

Due to non-normality of data distribution (ShapiroWilk test, $\mathrm{p}<0.05)$, data were presented as median and $25^{\text {th }}$ and $75^{\text {th }}$ percentiles. The Mann-Whitney test was used for comparisons of independent, quantitative variables between two unpaired samples. All analyses were performed using the Stata 11.0 software package, and significance level was set at $5 \%$.

\section{Results}

A total of 36 patients (16 men) were interviewed. Age varied between 19 and 76 years (51.6 \pm 15.2 years), 11 were older than 60 years, 14 were aged between 45 and 59 years and the others were younger than 44 years. Almost half of them were overweight (BMI > 25). With respect to educational attainment, $69.44 \%$ had some or completed primary education (Table 1 ).

With respect to the types of surgeries performed, 18 (50\%) patients underwent mitral valve replacement, 16 $(44.4 \%)$ patients underwent aortic valve replacement and $2(5.6 \%)$ underwent mitral and aortic valve replacement, concomitantly. Nineteen patients $(52.8 \%)$ received bioprosthesis and 17 (47.2\%) mechanical prosthesis \%). The causes of valve replacement are described in Table 2. Mean postoperative period, which corresponded to the day of the questionnaire, was $32.5 \pm 15.5$ months (8 - 61 months).

In our population, $27.8 \%$ of patients were working, and $72.2 \%$ were retired, out of work or housewives. Regarding 
Table 1 - Distribution (absolute and relative frequencies) of demographic data by sex

\begin{tabular}{|c|c|c|c|c|c|c|c|}
\hline \multirow{2}{*}{ Categories } & \multirow{2}{*}{ Variables } & \multicolumn{6}{|c|}{ Sex } \\
\hline & & Women & $\%$ & Men & $\%$ & Total & $\%$ \\
\hline \multirow{5}{*}{$\begin{array}{l}\text { Marital } \\
\text { status }\end{array}$} & Single & 4 & 11.11 & 2 & 5.55 & 6 & 16.66 \\
\hline & Married & 9 & 24.99 & 13 & 36.11 & 22 & 61.11 \\
\hline & Divorced/separated & 4 & 11.11 & 1 & 2.77 & 5 & 13.88 \\
\hline & Widow(er) & 3 & 8.33 & 0 & 0 & 3 & 8.33 \\
\hline & Total & 20 & 55.55 & 16 & 44.44 & 36 & 100 \\
\hline \multirow{4}{*}{ Education } & Illiterate & 2 & 5.55 & 2 & 5.55 & 4 & 11.11 \\
\hline & Primary & 13 & 36.11 & 8 & 22.22 & 21 & 58.33 \\
\hline & Secondary and higher education & 5 & 13.88 & 6 & 16.66 & 11 & 30.55 \\
\hline & Total & 20 & 55.55 & 16 & 44.44 & 36 & 100 \\
\hline \multirow{4}{*}{ BMI } & Normal & 6 & 16.66 & 6 & 16.66 & 12 & 33.33 \\
\hline & Overweight & 8 & 22.22 & 9 & 24.99 & 17 & 47.22 \\
\hline & Obesity & 6 & 16.66 & 1 & 2.77 & 7 & 19.44 \\
\hline & Total & 20 & 55.55 & 16 & 44.44 & 36 & 100 \\
\hline \multirow{4}{*}{ Age } & $<44$ years & 8 & 22.22 & 3 & 8.33 & 11 & 30.55 \\
\hline & 45 - 59 years & 6 & 16.66 & 8 & 22.22 & 14 & 38.88 \\
\hline & $>60$ years & 6 & 16.66 & 5 & 13.88 & 11 & 30.55 \\
\hline & Total & 20 & 55.55 & 16 & 44.44 & 36 & 100 \\
\hline
\end{tabular}

Table 2 - Distribution of the types and causes of heart valve replacement

\begin{tabular}{|c|c|c|c|c|c|}
\hline Valve replacement & Material & Valve failure & Stenosis & Double replacement & Total \\
\hline \multirow{2}{*}{ Mitral } & Tissue & 5 & 1 & 1 & 7 \\
\hline & Metallic & 10 & & 1 & 11 \\
\hline \multirow{2}{*}{ Aortic } & Tissue & 5 & & 6 & 11 \\
\hline & Metallic & 2 & 3 & & 5 \\
\hline \multirow{2}{*}{ Mitral + aortic } & Tissue & & 1 & & 1 \\
\hline & Metallic & & 1 & & 1 \\
\hline Total & & 22 & 6 & 8 & 36 \\
\hline$\%$ & & $61.1 \%$ & $16.7 \%$ & $22.2 \%$ & $100 \%$ \\
\hline
\end{tabular}

the family income, $55.6 \%$ received less than Brazilian reals (BRL) 1,000; 33.3\% gained from BRL 1,000 to BRL 2,000; $8.3 \%$ from BRL 2.000 to 3.000; and 2.8\% received more than BRL3,000.
All patients reported performing physiotherapy during hospitalization, only $2.8 \%$ underwent cardiac rehabilitation in the postoperative period, $100 \%$ reported to perform clinical tests periodically and $41.7 \%$ 
practiced physical exercise regularly, mostly walking, 2-3 times a week.

With respect to the SF-36 domains, the highest scores were found for social functioning (mean of 89.25), and the lowest scores for mental health (mean of 54.4). Comparisons of SF-36 results and sociodemographic data between mechanical prosthetic valves and bioprostheses are found in Table 3.

Comparison of SF-36 scores by the type of prosthesis implanted showed that emotional functioning scores were significantly higher in the emotional functional domain for patients with mechanical prosthesis compared with those with bioprosthesis (0.0084) (Table 3 ). In the analysis by valve replaced, patients with aortic valve replacement showed significantly higher scores for the functional capacity domain ( $p=0.0047)$. In addition, significantly higher scores were found in the functional capacity domain for men compared with women ( $\mathrm{p}=$ 0.0264). Considering the marital status, married patients showed significantly higher scores in the general health $(p=0.0287)$ and social functioning $(p=0.0063)$ domains compared with single patients.

Regarding the income of participants, those who received more than BRL1,000 showed significantly higher mean scores for the pain $(p=0.0375)$ and general health (0.0078) domains. Working patients showed significantly higher scores in functional capacity $(\mathrm{p}=$ 0.0112) compared with non-working patients. Finally, considering physically active versus physically inactive individuals, mean scores of physical functioning $(\mathrm{p}=0.0385)$, general health $(\mathrm{p}=0.0371)$ and social functioning $(p=0.0069)$ domains were significantly higher in physically active individuals.

No difference in SF-36 scores was found between individuals according to race/ethnicity, educational attainment, age, or BMI.

The item of the SF-36 questionnaire that compares current QoL of patients with the QoL one year before showed that, as compared with the QoL one year before, $22.2 \%$ of the patients reported that current QoL is much better; $33.33 \%$ a little better and $36.1 \%$ reported that current QoL is almost the same; $8.33 \%$ a little worse, and $0 \%$ much worse.

When analyzed by gender, in general, male patients reported a better QoL $-62.5 \%$ of men reported that current QoL is a little or much better than one year before. When analyzed by the type of valve implanted (mechanical vs. bioprosthetic valves and aortic vs. mitral), patients with bioprosthesis and patients with aortic prosthesis referred a better QoL nowadays compared with one year before.

Table 3 - Comparison between mechanical and bioprosthetic valves of the SF-36 scores in each domain

\begin{tabular}{|c|c|c|c|c|c|c|c|}
\hline \multirow{3}{*}{ Domain } & \multicolumn{7}{|c|}{ Type of prosthesis } \\
\hline & \multicolumn{3}{|c|}{ Mechanical } & \multicolumn{3}{|c|}{ Bioprosthesis } & \multirow[b]{2}{*}{ p } \\
\hline & Median & $\begin{array}{c}25^{\text {th }} \\
\text { percentile }\end{array}$ & $\begin{array}{c}75^{\text {th }} \\
\text { percentile }\end{array}$ & Median & $\begin{array}{c}25^{\text {th }} \\
\text { percentile }\end{array}$ & $\begin{array}{c}75^{\text {th }} \\
\text { percentile }\end{array}$ & \\
\hline Functional capacity & 65 & 55 & 75 & 75 & 60 & 80 & 0.12 \\
\hline Physical functioning & 75 & 75 & 100 & 100 & 75 & 100 & 0.46 \\
\hline Pain & 84 & 62 & 84 & 84 & 62 & 100 & 0.59 \\
\hline General health & 72 & 67 & 82 & 72 & 62 & 82 & 0.93 \\
\hline Vitality & 70 & 65 & 75 & 70 & 60 & 75 & 1 \\
\hline Social functioning & 100 & 75 & 100 & 100 & 75 & 100 & 0.44 \\
\hline Emotional functioning & 100 & 100 & 100 & 67 & 67 & 100 & $0.0084^{*}$ \\
\hline Mental health & 60 & 52 & 60 & 56 & 44 & 60 & 0.66 \\
\hline
\end{tabular}




\section{Discussion}

The results of the present study indicate that the patients undergoing heart valve replacement reported a satisfactory QoL according to the scores achieved in most of the SF-36 domains. Similar findings were reported by Grady et al. ${ }^{11}$ that evaluated 2,524 patients undergoing several cardiac surgeries and showed that the QoL of patients undergoing replacement of heart valve improved from baseline to six months after surgery and remained relatively stable through 3 years. This result demonstrates that the QoL of these patients markedly improves after valve replacement surgery compared with the preoperative period.

Except for the SF-36 domains functional capacity, physical functioning and mental health, the SF-36 scores of our population were similar to the mean scores obtained from residents of Sao Paulo city, previously published..$^{12}$ This is in agreement with another study showing that patients undergoing cardiac operations reported comparable or even higher SF-36 scores compared with the general population of the same area. ${ }^{11}$

In the analysis of the type of heart valve implanted (biological versus mechanical), we found a statistically significant difference only for the emotional functioning domain $(p=0.0084)$. Vicchio et al., ${ }^{13}$ also concluded in a study about the QoL of octogenarians who had undergone heart valve replacement that the type of the valve had no influence on their QoL.

In addition, our results were similar to those reported in a study that evaluated the QoL of 136 patients assessed two years after aortic valve replacement. The authors compared the QoL of patients with bioprostheses and patients with mechanical prostheses and found no statistically significant difference. ${ }^{14}$ Compared with this study, our group reported higher mean scores for all SF36 domains, except for mental health and pain.

In the mental health domain, which encompasses depression and anxiety, we found low scores, with a mean of 54.44. These data seem to differ from the results of Aboud et al., ${ }^{14}$ who observed higher scores in a study with a similar sample (mean of 69.6). However, our results seem to be not that different considering the mean age of our sample, 51 years and 6 months old, and considering that most of our sample had a bioprosthesis, since the mean score in the mental health domain in the equivalent group was 56.

According to Ruo et al., ${ }^{15}$ depression and anxiety were found in $20 \%$ of the patients with coronary artery disease.
The authors suggested that efforts should be made in the treatment of depression and anxiety in cardiac patients. Although we studied a different population, heart valve replacement surgery can also have a negative impact on the perception of health and performance of physical exercise, leading to worsening physical impairment and QoL, similarly to what was reported by Ruo et al. ${ }^{15}$

The low score in health perception may be explained by the fact that many patients feel frustrated for not performing all the activities they wished to do, since expectations in the postoperative period may be high. Góis et al., ${ }^{16}$ support this theory in the study about QoL in the pre and postoperative periods of myocardial revascularization to explain the deterioration in social functioning and mental health.

These low scores can also be explained by the lack of physical activity, as $58.3 \%$ of the patients were physically inactive, which can have a negative impact on the QoL, on emotional status and on health. The positive impact of physical activity was well demonstrated in our study, as we found a statistically significant difference in three of the eight domains of the SF-36 questionnaire. Physically active individuals had better scores compared with physically inactive ones.

Exercise increases work capacity and improves the QoL. ${ }^{17}$ Araújo et al., ${ }^{18}$ showed that physical activity has a positive effect on emotional health. Veigas \& Gonçalves, ${ }^{19}$ in a study on 207 individuals, reported the impact of physical activity on anxiety and stress in younger individuals and on depression in older individuals. The incidence of these conditions was lower in physically active than inactive ones.

In addition, a considerable number of patients reported to be unsatisfied with the fact that they did not return to work and to feel insecure to perform activities that require greater effort. These findings are in accordance with another study ${ }^{20}$ on acute myocardial infarction patients which reported that an inability to return or be fit for work had a negative influence on QoL. ${ }^{20}$

The present study has some limitations including the different periods of time from the surgery between the patients and lack of information of ventricular function, which may have had some influence on the QoL. Also, the sample size was small due to the low adherence to the treatment by the patients during the study period.

In the present study, patients undergoing aortic valve replacement showed better scores in functional 
capacity as compared with those undergoing mitral valve replacement (73.12 and 64.16, respectively, $\mathrm{p}<0.05)$. This difference may be related to the prevalence of male patients in the aortic valve replacement group, considering the greater physical capacity of men compared with women.

\section{Conclusion}

The QoL of the patients undergoing heart valve replacement improves considerably after the surgery, except for the mental health domain, probably due to the low practice of physical activity. The type of prosthesis seems not to influence the QoL or the patients in the late postoperative period.

\section{Author contributions}

Conception and design of the research: Molero Junior JC, Breda JR. Acquisition of data: Molero Junior JC, Breda JR. Analysis and interpretation of the data: Molero Junior JC, Raimundo RD, Amaral JAT, Abreu LC, Breda JR. Statistical analysis: Raimundo RD, Amaral JAT, Abreu LC, Writing of the manuscript: Molero Junior JC, Raimundo RD, Abreu LC, Breda JR. Critical revision of the manuscript for intellectual content: Molero Junior

\section{References}

1. Holmes C, Briffa N. Patient-Reported Outcome Measures (PROMS) in patients undergoing heart valve surgery: why should we measure them and which instruments should we use? Open Heart. 2016;3(1):e000315. doi:10.1136/openhrt-2015-000315.

2. Pomerantzeff PM, Barbosa GV, Filho BSS, Brandão CMA, Ribeiro EJ Costa FDA, et al. Diretrizes de Cirurgias nas Valvopatias. Arq Bras Cardiol. 2004; 82: (Supl. 5):22-33.

3. Campos NLKL, Andrade RR, Silva MAM. Anticoagulação oral em portadores de próteses valvares cardíacas mecânicas. Experiência de dez anos. Rev Bras Cir Cardiovasc. 2010;25(4):457-65.

4. Tasca R, Tasca MG, Amorim PAA. Evaluation of Prosthetic Valves with Echocardiography and Doppler Ultrasound. Rev bras ecocardiogr imagem cardiovasc. 2011;24(3):58-83

5. Almeida AS, Picon PD, Wender OCB. Resultados de pacientes submetidos à cirurgia de substituição valvar aórtica usando próteses mecânicas ou biológicas. Rev Bras Cir Cardiovasc. 2011;26(3):326-37.

6. Monteiro R, Braile DM, Brandau R, Jatene FB. Qualidade de vida em foco. Rev Bras Cir Cardiovasc. 2010;25(4):568-74

7. Berg SK, Rasmussen TB, Thrysoee L, Lauberg A, Borregaard B, Christensen AV, et al. DenHeart: Differences in physical and mental health across cardiac diagnoses at hospital discharge. J Psychosom Res. 2017 Mar;94:1-9. doi: 10.1016/j.jpsychores.2017.01.003. Epub 2017 Jan 6.

8. Ciconelli RM, Ferraz MB, Santos W, Meinão I, Quaresma MR. Tradução para a língua portuguesa e validação do questionário genérico de
JC, Raimundo RD, Amaral JAT, Abreu LC, Breda JR. Supervision / as the major investigador: Breda JR.

\section{Potential Conflict of Interest}

No potential conflict of interest relevant to this article was reported.

\section{Sources of Funding}

This article is part of the thesis of master submitted by José Carlos Molero Junior, from Faculdade de Medicina do $\mathrm{ABC}$.

\section{Study Association}

This study is not associated with any thesis or dissertation work.

\section{Ethics approval and consent to participate}

This study was approved by the Ethics Committee of the Faculdade de Medicina do $A B C$ under the protocol number $043 / 2011$. All the procedures in this study were in accordance with the 1975 Helsinki Declaration, updated in 2013. Informed consent was obtained from all participants included in the study.

avaliação de qualidade de vida SF-36 (Brasil SF-36). Rev Bras Reumatol. 1999;39(3):143-50.

9. Nogueira CRSR, Hueb W, Takiuti ME, Girardi PBMA, Nakano T, Fernandes $\mathrm{F}$, et al. Qualidade de vida após revascularização cirúrgica do miocárdio com e sem circulação extracorpórea. Arq Bras Cardiol. 2008;91(4):238-44

10. Takiuti ME, Hueb W, Hiscock SB, Nogueira CRSR, Girardi P, Fernandes F, et al. Qualidade de vida após revascularização cirúrgica do miocárdio, angioplastia ou tratamento clínico. Arq Bras Cardiol. 2007;88(5):537-44.

11. Grady KL, Lee R, Subacius H, Malaisrie SC, McGee EC, Kruse J, et al. Improvements in Health-Related Quality of Life Before and After Isolated Cardiac Operations. Ann Thorac Surg. 2011;91(3):777-83.

12. Lima MG, Barros MBA, César CLG, Goldbaum M, Carandina L, Ciconelli RM. Health related quality of life among the elderly: a population-based study using SF-36 survey. Cad Saúde Púbica. 2009;25(10):2159-67

13. Vicchio M, Corte AD, Santo LSD, Feo MD, Caianiello G, Scardone M, et al. Tissue versus Mechanical Prostheses: Quality of Life in Octogenarians. Ann Thorac Surg. 2008;85(4):1290-5.

14. Aboud A, Breuer M, Bossert T, Gummert JF. Quality of life after mechanical vs. biological aortic valve replacement. Asian Cardiovasc Thorac Ann. 2009; 17(1):35-8.

15. Ruo B, Rumsfeld JS, Hlatky MA, Liu H, Browner WS, Whooley MA. Depressive symptoms and health-related quality of life. JAMA. 2003;290(2):215-21. 
16. Góis CFL, Dantas RAS, Torrati FG. Qualidade de vida relacionada à saúde antes e seis meses após a cirurgia de revascularização do miocárdio. Rev Gaúcha Enferm. 2009;30(4):700-7.

17. Marchionni N, Fattirolli F, Fumagalli S, Oldridge N, Del Lungo F, Morosi $\mathrm{L}$, et al. Improve exercise tolerance and quality of life with cardiac rehabilitation o folder patients after myocardial infarction: results of randomized, controlled trial. Circulation. 2003;107(17):2201-6.

18. Araújo SRC, Mello MT, Leite JR. Transtornos de ansiedade e exercício físico. Rev Bras Psiquiatr. 2007;29(2):164-71.
19. Veigas J, Gonçalves M. A influência do exercício físico na ansiedade, depressão e stress. Internet. [Acesso em 17 de julho 2018]. Disponível : www.psicologia.com.pt

20. Brown N, Melville M, Gray D, Young T, Munro J, Skene AM, et al. Quality of life four years after acute myocardial infarction: short form 36 scores compared with a normal population. Heart.1999;81(4):352-8. 